\title{
Representações sobre a inserção na vida ativa de jovens com trissomia 21
}

【 José Maria Fernández Batanero* e José Fernando Machado de Oliveira* *

\section{Resumo}

Partindo da idéia de que um processo/método de TVA deve ser capaz de se adaptar às rápidas mudanças do mundo global, conferindo uma adequada preparação para o mundo de trabalho, gerando expectativas positivas, desenvolvendo nos jovens com potencial para serem integrados profissionalmente as características pessoais e competências necessárias Este estudo dá, igualmente, na nossa perspectiva, um contributo importante para a compreensão dos fatores que podem levar a um aumento da empregabilidade das pessoas com esta patologia e dos jovens deficientes em geral.

Palavras-chave: Trissomia 21 . Syndrome de Down. Instrução especial. Mental atrasa. Transição à vida ativa. Orientação profissional. Integração.

\section{Abstract \\ Representations on the active life inserction of trisonomy 21 young people}

Starting of the idea that a process/method of transition to the active life must be able to adapt to the fast changes in a global world, conferring a suitable preparation for the world of the work, generating positive expectations, preparing to the young people for its professional integration and equipping them with the necessary competitions. From this idea, we presented/displayed this work that contributes of important form to the compression of factors that can lead to an increase of the use of the people with trisonomy 21 and deficient young people in general.

Keywords: Trisonomy 21. Syndrome of Down. Special education. Mental delay. Transition to the active life. Occupational direction. Integration.

\section{Resumen}

\section{Representaciones sobre la inserción en la vida activa de jóvenes con trisomía 21}

Partimos de la idea de que un proceso o estrategia de transición a la vida activa (TVA) debe ser capaz de promover adaptarse a los rápidos cambios en un mundo global, confiriendo una adecuada preparación para el mundo del trabajo, generando expectativas positivas, preparando a los jóvenes para su integración profesional y dotándolos de las competencias necesarias. Desde esta punto de partida, presentamos este trabajo que contribuye, creemos que de forma importante, a la comprensión de factores que pueden conducir a un aumento del empleo de las personas con trisomía 21 y de jóvenes deficientes en general.

Palabras clave: Trisomía 21. Síndrome de Down. Educación especial. Retraso mental. Transición a la vida activa. Orientación ocupacional. Integración.

" Doutor em Filosofia e Ciência da Educação; Professor Titular da Universidade de Sevilha, ES. E-mail: batanero@us.es

"* Pós-Graduado em Educação Especial; Professor da Escola Secundária de Cascais, PT. E-mail: jfernandooliveira@sapo.pt 


\section{Introdução}

As questões da transição para a vida activa (TVA) são cada vez mais prementes no contexto global actual. As tecnologias da informação e comunicação (TIC) permitiram a mundialização da economia, levando a alterações das condições de trabalho e acentuando as crises de desemprego, atenuando a relação desenvolvimento/criação de empregos levaram a que expansão econômica nem sempre signifique criação de emprego (LOPES et al., 2000).

Os jovens, na transição escola-trabalho, enfrentam atualmente, um cenário completamente diferente do encontrado pelos seus pais. Ter trabalho na mesma empresa durante a vida inteira é hoje em dia uma situação rara. Do mesmo modo os requisitos pedidos pelos empregadores, os tipos de carreira e as características do trabalho alteraram-se substancialmente.

Nestas condições, as questões postas pela transição escola-emprego, designadas genericamente por "transição para a vida activa" adquiriram especial relevância. Neste âmbito a escola tem sido censurada por não ser capaz de fornecer os conhecimentos e as competências que a vida profissional exige, nem de ser capaz de se adaptar, com a rapidez necessária, a um mundo onde as condições de trabalho, tanto locais como internacionais se alteraram substancialmente.

Mas, se os jovens em geral enfrentam estes problemas o que dizer de pessoas com deficiência? Será que os processos ou metodologias que formam e preparam estes jovens para a transição se adaptaram e são atualmente adequados às mudanças impostas pelo contexto global? Qual o melhor dos métodos de transição para a vida ativa? Existirá um que se distinga conferindo as competências que levem à obtenção de meIhores resultados na transição escola-trabaIho? Haverá algum método que seja mais adequado a jovens com trissomia 21 ou poder-se-ão aplicar os métodos utilizados com os jovens com desvantagens em geral? Que expectativas, que sonhos têm estes alunos relativamente ao seu processo de transição e relativamente à sua integração no mundo do trabalho? $\mathrm{Na}$ perspectiva destes jovens qual é o papel da Educação Especial e qual é o papel dos professores em geral, na preparação dos processos de transição para a vida adulta? Qual a sua influência / relevância no desenvolvimento dos seus ideais ou representações? A escola desenvolve mecanismos, estabelece ligações com a comunidade local que facilitem ou apóiem os seus alunos na fase de transição? Que dificuldades esperam os alunos nessa transição? Como aumentar a empregabilidade destes jovens?

Atendendo a que na transição para a vida activa da pessoa com trissomia 21 se podem considerar os mesmos aspectos chave importantes para qualquer adolescente (CASAL et al., 1991 apud MARTINS, 1999), todas estas interrogações darão resposta a uma grande questão: tem a escola mecanismos, processos e metodologias que preparem os seus alunos que não querem prosseguir estudos, e em particular os que apresentam necessidades educativas especiais (n.e.e.), para a transição para a vida activa?

Definiu-se como objetivo geral desta investigação o seguinte:

Conhecer as representações sobre a integração na vida activa de alunos trissômicos.

Para atingir o referido objetivo o trabaIho foi separado em duas partes: 
Parte I - Métodos de TVA: o contexto das representações sociais

Parte II - Representações sociais: o retrato

A parte I que agora se apresenta, justifica-se relativamente às representações, pelos princípios implícitos a estas teorias que se referem a seguir em termos muito genéricos:

As Teorias das Representações Sociais, apresentadas pela primeira vez por Moscovici em 1961, são em termos muito gerais construções mentais sobre a realidade vivida pelo indivíduo. São, portanto, a sua tradução cognitiva da realidade processada e transformada pelo seu intelecto (nesse processo de construção estão envolvidas a cognição, a afetividade, as influências culturais, etc.). Essas "representações estão presentes tanto 'no mundo' como 'na mente' [pelo que] devem ser pesquisadas em ambos os contextos" (GUARESCHI; JOVCHELOVITCH, 1998, p. 47).

estudo e conhecimento das representações, diferencia-se da Psicologia Social mais individualizante, pois, além de permitir conhecer os sujeitos do ponto de vista de determinado tema, pode servir, também, para caracterizar um determinado grupo de indivíduos apesar das diferenças entre eles.

Para o conhecimento das representações não se deve, conseqüentemente, esquecer os factores que têm grande influência na escolha dos elementos que aparecem como estruturadores da conceitualização das representações: factores culturais, modos de vida, diversidade contextual. "Portanto, para estudá-las, em primeiro lugar é indispensável conhecer as condições de contexto em que os indivíduos estão inseridos mediante a realização de uma cuidadosa análise contextual" (FRANCO, 2004, p. 170).
Atendendo ao que foi dito, esta parte do trabalho pretende compreender as condições do contexto escolar relativas aos processos de TVA para melhor compreender as representações destes jovens.

\section{Metodología}

Os objetivos relacionados com esta parte do trabalho foram os seguintes:

\section{Objetivo principal}

Identificar factores, como, por exemplo, elementos pedagógicos fornecidos aos alunos, competências desenvolvidas no processo formativo, envolvimento da família no processo formativo, meio geográfico de origem (rural ou urbano) que podem intervir ou influenciar os ideais e sonhos manifestados pelos alunos.

\section{Objetivos secundários}

- Identificar e listar os principais métodos de transição para a vida activa utilizados nas escolas com alunos com deficiência;

- identificar e listar os principais métodos de transição para a vida activa utilizados com os jovens com trissomia 21 em formação;

- identificar e listar os principais factores necessários para uma boa integração profissional de pessoas com deficiência (percepcionados pelos técnicos que trabalham em TVA).

- identificar e listar as principais dificuldades sentidas pelos professores do Apoio Educativo e/ou outros técnicos na aplicação de métodos de TVA a jovens com deficiência.

A metodologia utilizada pode resumir-se esquematicamente da forma que se segue: 


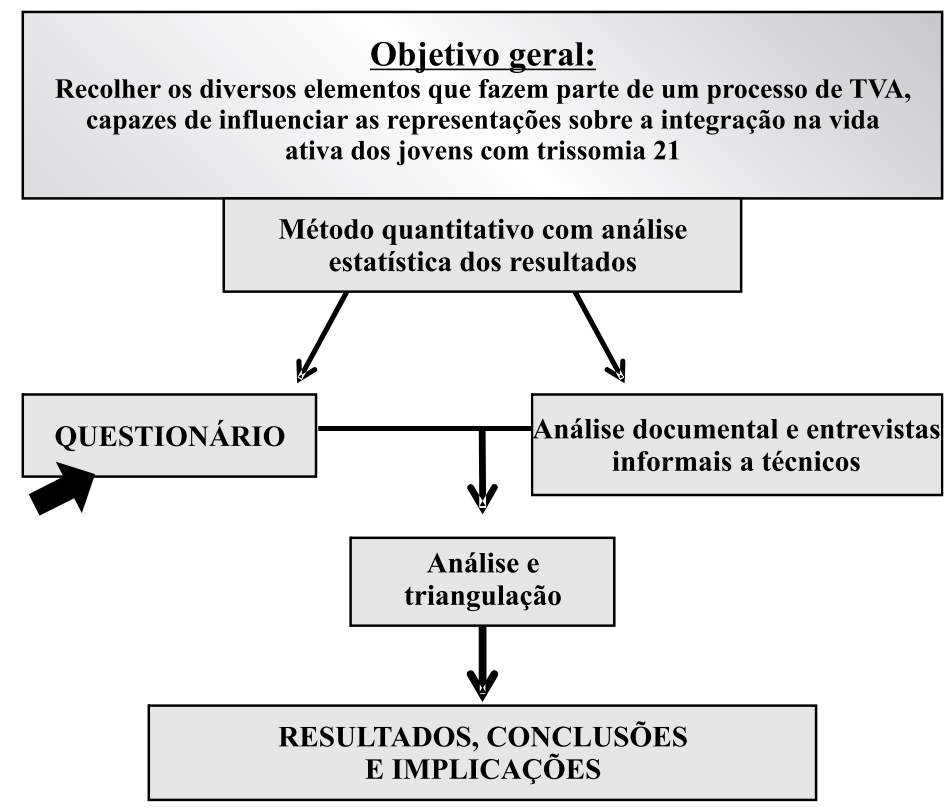

Utilizou-se, portanto, uma metodologia quantitativa com análise estatística, paramétrica e não paramétrica, dos dados recolhidos através do questionário (principal instrumento de recolha de dados). O questionário continha perguntas abertas e fechadas. A análise estatística das questões fechadas foi feita com auxílio do programa informático SPSS 11.5. As perguntas abertas foram submetidas a análise indutiva. Quanto à validação do questionário optou-se por uma validação realizada por um painel de 5 peritos.

\section{Seleção da amostra}

Para seleção da amostra utilizaram-se duas técnicas de amostragem. Num primeiro momento o processo baseou-se num:

Processo de amostragem estratificada não proporcional assente em dois critérios:

1 - Critério de caráter geográfico baseado no NUTS II (territórios estatísticos nacio- nais) onde se escolheu-se a região de Lisboa e Vale do Tejo (RLVT);

2 - Dentro das escolas de LVT selecionou-se um estrato correspondente a escolas que podem ser frequentadas por jovens com T21 com as características procuradas para este estudo, ou seja, escolas com segundos e terceiros ciclos.

A segunda fase decorreu de acordo com o processo de amostragem casual simples. Como tal, para se obter uma amostra representativa o questionário foi enviado a cerca de 50\% (150 escolas) das escolas selecionadas no primeiro momento da amostragem. As escolas que receberam questionários foram escolhidas pela Técnica dos números aleatórios.

Obteve-se uma percentagem de respostas correspondente a 35\% (53 escolas) de escolas, o que corresponde a cerca de $17 \%$ do Universo Alvo. 
Elegeram-se como respondentes todos os técnicos que nas escolas são potenciais responsáveis pela implementação de programas de TVA, a saber:

\section{- Professores do Ensino Especial / Apoio} Educativo;

- Psicólogos escolares, normalmente responsáveis pelos Serviços de Orientação e Psicologia (SPO).

Foram também considerados como respondentes:

- Outros professores que não os do Apoio Educativo que tivessem, na escola, funções relacionadas com TVA.

\section{Função do professor na escola}

\begin{tabular}{|l|l|l|}
\hline \multicolumn{2}{|l|}{} & $\begin{array}{l}\text { Freqüência } \\
\text { relativa (\% } \\
\text { de valores } \\
\text { válidos) }\end{array}$ \\
\hline Válidos & $\begin{array}{l}1 \text { Professor do } \\
\text { EnsinoEspecial / } \\
\text { Apoios educativos }\end{array}$ & 86,8 \\
\cline { 2 - 3 } & 2 Psicólogo & 11,3 \\
\cline { 2 - 3 } & $\begin{array}{l}3 \text { Outra relacionada } \\
\text { com TVA }\end{array}$ & 1,9 \\
\cline { 2 - 3 } & Total & 100,0 \\
\hline
\end{tabular}

Aproximadamente $87 \%$ dos professores respondentes são Professores do Ensino Especial, 11,3\% pertencem aos Serviços de Psicologia e Orientação das escolas (SPO). Uma reduzida proporção exerce outras funções relacionadas com TVA, nomeadamente Técnico de Inserção.

Quanto à localização da escola verificouse que as escolas respondentes pertencem na sua esmagadora maioria $(86,8 \%)$ a fregue- sias urbanas (APU - Área Propriamente Urbana). Uma minoria pertence a freguesias mediamente urbanas (AMU) e propriamente rurais (APR). As escolas menos representadas neste estudo pertencem a freguesias rurais.

Estes resultados, apesar de diferirem dos dados referentes à \% de freguesias urbanas (APU e AMU) na região de RLVT que é de 68\% não surpreendem, pois a localização das escolas depende diretamente da densidade populacional e, é no primeiro tipo de região que se concentra a grande maioria da população (86\% - note-se a coincidência entre a porcentagem de escolas urbanas que responderam a este inquérito e a \% de população nestas APU).

No que diz respeito aos respondentes verifica-se que cerca de $51 \%$ destes técnicos estavam a aplicar processos de TVA nas suas escolas, enquanto os restantes não o estavam a fazer no ano letivo 2005/2006.

\begin{tabular}{|l|l|r|c|}
\hline \multicolumn{2}{|l|}{} & Freqüência & $\begin{array}{c}\text { Freqüência } \\
\text { relativa }\end{array}$ \\
\hline Válidos & 1 Sim & 27 & 50,9 \\
\hline & 2 Não & 26 & 49,1 \\
\hline & Total & 53 & 100 \\
\hline
\end{tabular}

No que concerne à experiência dos respondentes em termos de aplicação de processos de TVA verifica-se o seguinte:

- Relativamente aos professores que têm TVA neste ano letivo, 84 \% já possuíam experiência anterior nesta área;

- $95 \%$ dos professores sem qualquer experiência em TVA não estão a aplicar processos de TVA em 2005/2006, o que significa que só $5 \%$ dos professores sem experiência estão a trabalhar nessa área.

Destes dados podem tirar-se duas conclusões: 
- A maioria dos professores que aplicam processos de TVA aos seus alunos já possuía experiência nessa área. A experiência dos professores parece ser, então, um fator preponderante na existência de métodos de TVA nas escolas;

- Relativamente aos processos de TVA, as escolas fazem um aproveitamento muito elevado da experiência dos seus professores.

Para saber se são os professores de apoio ou os outros técnicos que mais aplicam ou são responsáveis por processos de TVA fez-se o cruzamento entre os dados sobre as funções exercidas e sobre a aplicação de processos de TVA em 2005/2006. As conclusões podem ser retiradas do gráfico que se segue:

Comparando as percentagens de psicólogos que estão a aplicar processos de TVA com a respectiva taxa de Professores de Apoio Educativo (PA), verifica-se que a proporção relativa é maior no primeiro grupo $(83 \%$ dos psicólogos respondentes estão a aplicar processos de TVA, enquanto nos PA essa percentagem é de apenas $46 \%$ - que é bastante pouco se atendermos às funções destes profissionais).

\section{Conclusões}

A análise dos dados permite tirar uma série de conclusões relativas ao funcionamento de processos de TVA nas escolas portuguesas e metodologias aplicadas aos jovens com necessidades educativas especiais (NEE) com especial relevância para os portadores de trissomia 21. Definiu-se, com base em estudos oficiais e na literatura existente, que a idade que estes jovens teriam que possuir para frequentar um processo desta natureza estaria compreendida entre os $13 \mathrm{e}$ os 18 anos, recomendando-se que comecem o mais cedo passível.
Em termos de escolas com processos de TVA a funcionar em 2005/2006 verifica que:

- do total de escolas respondentes ao questionário, $47 \%$ - uma percentagem superior à que prevíamos (a nossa hipótese era a de que a percentagem de escolas que não aplicam processos de TVA seria muito superior à das que aplicam) - aplicam métodos de TVA aos seus alunos com n.e.e. (onde as escolas incluem, também, jovens em risco de abandono escolar, com problemas atitudinais (emocionais / comportamentais) e outras dificuldades escolares).

- Em termos de metodologias utilizadas a situação não é tão boa, podendo ser mesmo classificada de caótica, senão vejamos:

- as 25 escolas que dizem estar a aplicar processos de TVA aos seus alunos indicaram 23 métodos diferentes;

- o total de métodos diferentes apresentados pelas 29 escolas que indicaram metodologias de TVA (4 dos processos de TVA não estão em funcionamento em 2005/2006) é de 26.

Ou seja, no ano letivo 2005/2006, havia praticamente um método diferente para cada escola, o que mostra que, em termos de TVA não existe qualquer normalização, nem grandes orientações ao nível das políticas educativas; As escolas implementam estes programas por iniciativa própria ou sem grande conhecimento das melhores metodologias.

Formas como as escolas implementam os programas de TVA

As escolas portuguesas implementam os seus programas de TVA de duas formas:

- 52\% delas, através de parcerias com instituições exteriores (normalmente, Estabelecimentos de Educação Especial, IPSS, CERCI 
ou Associações que asseguram a formação profissional dos alunos com n.e.e.), ao abrigo da Portaria 11 102/97 (PORTUGAL, 1997), de 3 de Novembro de 1997;

- 48\% por iniciativa própria e sem qualquer tipo de parceria.

O referido sistema de parcerias segue na maioria dos casos a seguinte formatação:

\section{- A formação acadêmica é assegurada} pela escola que também pode proporcionar as primeiras experiências de formação profissional (TVA) através da execução de pequenas tarefas nos seus serviços numa espécie de estágios de sensibilização;

- Paralelamente a esta pré-preparação ou depois dela, mas sempre em simultâneo com a formação acadêmica, o jovem inicia a sua formação profissional na instituição parceira responsável (que por sua vez estabelece parcerias com empresas e serviços da comunidade). Segue-se, se o processo decorrer de forma normal, a integração profissional e o respectivo acompanhamento póscolocação profissional.

Nas escolas sem parcerias a escola procura assegurar todo o processo de TVA, desde a Orientação Profissional até à integração profissional e acompanhamento pós-colocação profissional. A grande maioria das escolas não consegue ter programas de TVA completos faIhando nos dois últimos aspectos citados. Isto porque as escolas, apesar de terem professores de apoio educativo não dispõem de instrumentos (legislativos e outros) e meios próprios (financeiros e humanos - profissionais exclusivamente dedicados à TVA como, por exemplo Professor de Transição) que lhes permitam a concretizar a integração profissional ou fazer o devido acompanhamento pós-colocação profissional dos seus alunos.
Constata-se, também, que muitos dos processos de TVA (especialmente em escolas que os asseguram sem parcerias com instituições) funcionam com base na "carolice" e voluntarismo esforçado dos professores, em vez de numa base profissional apoiada e suportada por legislação, meios e condições de trabalho adequadas. Para agravar a situação, os técnicos, que revelam uma enorme vontade e realizam um imenso esforço para levar a cabo programas de TVA nas suas escolas, não são, na sua maioria, recompensados pelo seu esforço que muitas vezes nem sequer são reconhecidos. Como se constata, muitas vezes em Portugal, no campo da Educação, trabalha-se e produz-se à custa do esforço individual e voluntarioso de profissionais conscientes e responsáveis. Enquanto o sistema continuar a funcionar nesta base, não se pode esperar uma grande evolução, pois os esforços individuais não são concentrados e direcionados e o profissionalismo destes esforçados técnicos e professores não dará os devido frutos neste campo que deveria ter como resultado, processos de TVA devidamente organizados que conseguem a plena integração profissional dos jovens com trissomia 21 , capazes de tal, e de todos os outros jovens com n.e.e. ou oriundos de populações desfavorecidas, e ainda de todos os outros que não pretendam prosseguir estudos.

A nosso ver não existe uma verdadeira escola inclusiva se esta não procurar assegurar até ao final do processo acadêmico, a plena integração social e uma verdadeira inserção profissional dos jovens trissômicos (os que tiverem capacidades para isso) e dos restantes clientes da dita escola inclusiva. À luz do que foi referido urge, entre outras medidas, criar o cargo de Professor de Transição cujas funções terão por base a dedicação exclusiva aos projetos de TVA em todas as suas vertentes onde se incluem desde a coordenação do processo ao acompanhamento dos estágios. 
Podemos dizer, também, que os processos de TVA, apesar do reconhecimento da sua importância pelos sucessivos governos portugueses e pela Comunidade Européia, não têm sido verdadeiramente encarados como uma mais valia na formação dos jovens com desvantagens (uma mais valia para a sociedade que verá estas pessoas profissionalmente integradas, logo menos dependentes de subsídios que pesam no bolso dos contribuintes) nem como uma forma de se evitarem gastos futuros em segurança social (cujo sistema financeiro está cada vez mais depauperado em Portugal) em saúde (resultante da menor auto-estima, menor taxa de atividade - física e mental, ocupacional, etc., ou seja todo o rol de custos não quantificados que poderiam ser minorados ou excluídos com a integração profissional destas pessoas.

Noutras palavras o processo de TVA não é verdadeiramente visto como uma medida preventiva capaz de trazer benefícios e mais valias futuras - econômicas, sociais e outras - para o próprio interessado e para toda a sociedade. Estas mais valias estendem-se, também, ao próprio mercado de trabalho que, ao absorver estas pessoas, ganha em aspectos de que anda tão carenciado atualmente:

- maior humanização e respeito pelas diferenças em contraste com a formatação (normalização) dos trabalhadores;

- melhor noção de serviço social e de boas práticas e melhoria da imagem (em vez da impressão que o público tem de que as empresas apenas se preocupam consigo próprias e com o crescimento dos seus lucros, num olhar constante para o umbigo);

- menor grau de descriminação, etc.

Das transformações referidas resultarão ganhos ao nível da "consciência social" destas organizações de que beneficiarão, a curto prazo, toda a sociedade e os trabaIhadores em geral.

De pouco adiantam as medidas, tão do agrado dos governos (por serem fáceis de aplicar, mas de resultados muito questionáveis nos moldes desatualizados e desadequados em que é feita) de concessão de incentivos às empresas (principalmente financeiros) para apoio ao emprego de pessoas desfavorecidas, se a escola não for devida e condignamente envolvida em todo o processo de TVA. Sem a escola esses incentivos não passarão de paliativos que pouco minorarão o problema da integração, e que nunca o resolverão em grau satisfatório.

Acresce a isto, que num país como Portugal, em que a taxa de abandono escolar (sem conclusão da escolaridade obrigatória e sem qualquer tipo de formação apetecível para o mercado de trabalho) é muito elevada, este problema da TVA não pode ser de modo nenhum descurado. Se analisarmos quem abandona prematuramente a escola decerto chegaremos à conclusão de que se trata dos alunos mais carenciados e desfavorecidos por desvantagens diversas. Para estes alunos a instituição escola não oferece soluções para o seu futuro (que dada à situação de desfavorecimento não é tão distante quanto isso, necessitando, portanto, de soluções urgentes). É precisamente para muitos desses, e não apenas para os deficientes, que alguns dos métodos de TVA de maior aceitação foram desenhados. Para esses jovens, ter TVA, dizem vários professores, é um incentivo à permanência na escola pois descortinam aí a possível solução para as suas dificuldades, ao mesmo tempo que se apercebem, pela preocupação evidenciada pela instituição, que não são uma espécie de párias do sistema. É de referir que, enquanto para o ensino secundário se tem procurado oferecer soluções 
para aqueles que não querem prosseguir estudos (cursos de formação profissional nas escolas públicas) no terceiro ciclo, numa espécie de complexo elitista provocado pela necessidade de conclusão da escolaridade obrigatória, poucas soluções têm sido apresentadas a estes jovens. Recorda-se uma delas, praticamente extinta: as turmas de Currículos Alternativos ao abrigo do Despacho $n^{\circ}$ 22/SEEl/96 (PORTUGAL, 1996), destinadas a casos de sério risco escolar.

Ainda relativamente ao desenho do processo de TVA, a solução escola unida a uma instituição parceira que assegure a formação profissional pode ser a mais utilizada atualmente, mas pensamos não ser a verdadeira solução da equação "integração profissional", pois não se encontra assim tão espalhada pelo país e por outro lado estas instituições parceiras não surgem de um dia para o outro nem aplicam as melhores metodologias. Como já dissemos é preciso que as escolas, e conseqüentemente, os respectivos professores coordenadores dos projetos de TVA e responsáveis por estágios, sejam dotados de meios (para os professores: carga horária adequada, pagamento de gastos com deslocações para visitas a empresas, etc.) para produzirem ou darem continuidade a projetos de TVA próprios. Com isto ganharão as escolas que apresentarão, assim, um maior leque de soluções para os seus alunos (que não apenas a continuação de estudos, para o qual parecem, ainda hoje em dia, muito vocacionadas - mesmo as do terceiro ciclo) e ganhará a sociedade que deixará de ver todos os anos hordas de jovens estudantes sem qualquer formação profissional (e outros factores de empregabilidade que lhes dêem alguma garantia e confiança), e, muitas vezes, com formação escolar incompleta, engrossarem as fileiras do desemprego - cada vez maior nesta faixa etária - e da procura do primeiro em- prego. No aspecto da formação profissional destes jovens o ônus não pode caber exclusivamente às empresas que nem sequer estão vocacionadas para tal.

\section{Processo completo de TVA}

Consideramos que um processo de TVA completo deve prever/incluir sempre as seguintes etapas:

Orientação vocacional / profissional (avaliação, informação e orientação profissional propriamente dita);

Preparação pré-profissional que pode ser realizada através de estágios de sensibilização que podem servir também para despiste vocacional;

Formação profissional (com estágios em contexto real de trabalho - PA ou FPCR);

Colocação / integração na vida activa (integração profissional corresponde a contratação por parte da entidade patronal);

Acompanhamento pós-colocação profissional;

Fim do acompanhamento pós-integração (quando o aluno já está integrado na empresa de forma considerada segura).

Todo o processo deve ser individualizado e ir de encontro às reais necessidades do aluno. Assim, por exemplo, um aluno que já tem uma clara e realista, no sentido de ajustada às suas competências (cabe aos técnicos de TVA fazer essa avaliação) noção da profissão que pretende, não necessita de orientação profissional (a não ser que precise de maiores e melhores noções sobre o mundo do trabalho), no entanto isto não significa que não precise realizar estágios de sensibilização (que são o verdadeiro méto- 
do de os técnicos e o próprio interessado testarem / avaliarem a vocação e competências manifestadas). $\bigcirc$ importante é que o processo seja personalizado e de acordo com as necessidade (as etapas partir dos estágios da formação profissional, inclusive, são comuns a todos os formandos, o que pode variar é o tempo de formação).

\section{Metodologias de TVA aplicáveis a alunos com trissomia 21}

Os técnicos respondentes indicaram que $72 \%$ das metodologias utilizadas também se aplicam-se a T21 Assim, podemos dizer que nas escolas portuguesas se considera que, para esta deficiência, não é necessária a aplicação de uma metodologia específica de TVA.

No entanto os técnicos referem que existem métodos mais adequados à T21.

Modelo de Emprego Apoiado é, a nosso ver, entre os que estão a ser aplicados em Portugal, aquele que é mais adequado à trissomia 21 e a outras populações desfavorecidas. Algumas das vantagens deste modelo são as seguintes:

- É a metodologia que melhores resultados tem apresentado;

- Proporciona programas de TVA completos e adaptados ao sujeito;

- Aproveita todos os recursos da comunidade (através do desenvolvimento de redes de apoio que incluem empresas. No caso concreto das empresas, o modelo funciona na base de parcerias ativas bidirecionais que têm em conta quer as necessidades dos formandos a necessidade de apoio das empresas antes e após contratação destas pessoas, quer relativas ao processo de integração profissional, quer relativas à sua adaptação (ajudas técnicas, adaptação dos posto de trabalho, etc.) bem como em relação aos incentivos dados pelo Estado.);

- Desenvolve nos sujeitos as competências necessárias a uma boa integração profissional e procura trabalhar e melhorar todas as componentes da vida da pessoa em formação com vista a uma integração de sucesso durável ao longo do tempo (para isso o método tenta explorar todos os recursos da comunidade).

\section{Fatores que podem aumentar a empregabilidade das pessoas com trissomia 21}

A partir da análise dos factores para uma integração profissional de sucesso e das muitas entrevistas feitas a técnicos que preparam estes jovens deficientes para a transição para a vida activa e que fazem acompanhamento pós - integração profissional, apontamos as seguintes medidas que podem aumentar as possibilidades de integração profissional quer de pessoas com T21 quer com outras desvantagens:

- Implementação de melhores processos de TVA nas escolas e utilização das metodologias mais adequadas;

- Melhores sistemas de formação profissional (adaptados ao novo mundo do trabalho, às novas profissões, algumas delas janelas de oportunidade para os trissômicos) e menor duração temporal desses cursos de formação profissional;

- Melhor sistema de financiamento das instituições formadoras (com incentivos pela integração profissional de trabalhadores e não 
apenas simples "pagamentos por cabeça", que muitas vezes levam a prolongamentos artificiais do período de tempo de formação em vez de funcionarem como incentivo à tentativa de colocação profissional. Estender estes incentivos às escolas públicas, para que estas tenham meios de levar a cabo os seus próprios programas de TVA (tendo como produto final a integração profissional);

- Melhor sistema de incentivos (mais moderno, adaptado à nova realidade laboral, de fácil acesso e com menor complexidade em termos de cálculo dos montantes a receber por cada trabalhador deficiente admitido);

- Em caso de contratação, suspensão, em vez de corte, da pensão social até contratação sem termo. No caso desta não ocorrer e houver cessação do contrato, recuperação automática desta pensão após o fim do subsídio de desemprego a que o trabaIhador tenha direito. Assim, estes trabalhadores, caso o desejem, poderão, com os devidos apoios, continuar a procurar sem receios relacionados com a perda da pensão, uma nova integração profissional;

- garantir a qualidade do acompanhamento pós-colocação que deve servir para apoiar não apenas o trabalhador integrado, mas também a entidade patronal nos mais diversos aspectos relativos ao novo funcionário deficiente. Este acompanhamento pós - colocação deve ser garantido quer para as instituições de apoio a deficientes, quer às escolas públicas que têm processos de TVA para estas populações;

- Maior sensibilização às entidades patronais que devem começar a ver a contratação de pessoas deficientes como uma mais valia para as suas empresas e não como um favor que fazem à sociedade ou a alguns amigos.

\section{Fatores considerados como importantes para uma boa integração profissional}

A única dimensão representada nos factores considerados, pelos professores / técnicos das escolas com $2 .^{\circ}$ e $3 .^{\circ}$ Ciclos, como muito importantes para uma integração profissional de sucesso foi a dimensão sociocognitiva. As variáveis presentes dizem respeito às categorias Respeitar regras e Motivação (para o trabalho). Quanto às outras categorias de variáveis agrupadas nesta dimensão, verifica-se que os factores que dizem respeito à Adaptabilidade Psicológica obtiveram, dentro da classe Factores Importantes, médias relativamente baixas, mas os itens respeitantes à Autonomia foram os que obtiveram médias mais elevadas dentro da referida classe aproximando-se muito da classe dos factores classificados de Muito Importantes.

Note-se a ausência dimensão socioprofissional, o que significa que nenhuma das variáveis que integravam esta dimensão foi considerada como fazendo parte dos factores considerados importantes ou muito importantes para a integração profissional destes jovens.

Assim, e depois do que foi dito anteriormente, podemos afirmar que:

Os técnicos / professores de Apoio, tal como os empresários, consideram que os factores mais importantes para uma boa integração profissional são os que pertencem à dimensão sociocognitiva. Entre estes têm menos importância relativa os que dizem respeito à Adaptabilidade Psicológica seguindo-se os fatores da Autonomia. Os mais importantes são, então, as variáveis agrupadas nas categorias Respeitar regras e Motivação. 


\section{Referências}

AGÊNCIA EUROPÉIA PARA O DESENVOLVIMENTO EM NEE. Transição da escola para o emprego: relatório síntese 2002. Bruxelas, 2002.

ALTON, S. Including pupils with Down's Syndrome: information for teachers and learning support assistants: secondary. London: Down's Syndrome Association \& Scottish Down's Syndrome Association, 2005.

ALVAREZ, M. Orientación profisional. Barcelona: CEDECS, 1995.

ASTÚCIA, A. As pessoas com deficiência e o emprego. Revista Integrar, Lisboa, n. 18, maio/ago. 2002.

BERNARDINI et al. Transição da escola para o emprego. Denmark : European Agency for Development in Special Needs Education, 2002.

BOTELHO, A. P. A integração profissional das pessoas com deficiência: a resposta dos serviços públicos de emprego. Revista Integrar, Lisboa, n. 18, maio/ago. 2002.

COSTA, A. M. (Coord.). Educação e transição para a vida pós-Escolar de alunos com DIA. Lisboa: Instituto de Inovação Educacional, Ministério da Educação, 2004.

EUROPEAN AGENCY FOR DEVELOPMENT IN SPECIAL NEEDS DEVELOPMENT. Planos individuais de transição : apoiar a transição da escola para o emprego, 2006. Disponível em: <www.european.agency.org/transit/>. Acesso em: 27 nov. 2007.

- Transição da escola para o emprego: principais questões e opções enfrentadas pelos alunos com necessidades educativas especiais em 16 países europeus, 2002. Disponível em: <www.european.agency.org/transit/>. Acesso em: 27 nov. 2007.

FERNÁNDEZ BATANERO, J. M. et al. La formación continua ante la diversidad. In: BERMEJO CAMPOS, B.; MORALES LOZANO, J. A. (Coord.). Formación y trabajo: inserción laboral y desarrollo profesional. Sevilla: GID, 2000.

La función docente ante la multiculturalidad: atención a la diversidad. In: BARROSO OSUNA, J.; MORALES LOZANO, J. A. (Coord.). Formación docente y desarrollo profesional. Sevilla: GID, 2001.

FRANCO, M. Representaç̃̃es sociais, ideologia e desenvolvimento da consciência. Cadernos de pesquisa. São Paulo, v. 34, n. 121, p. 169-186, jan./abr. 2004. Disponível em: <www.scielo.br/pdf/cp/v34n121/a08n121.pdf>. Acesso em: 12 maio 2006.

GUARESCHI, P.; JOVCHELOVITCH, S. (Org.). Textos em representações sociais. 5. ed. Petrópolis: Vozes, 1998. 
LOPES, J. et al. Manual de transição para a vida activa. Lisboa: Edições Universitárias Lusófonas: DREL, 1999.

MARTINS, A. Importância dos aspectos sócio-relacionais em jovens com deficiência mental, em fase de transição para a vida activa. Lisboa: Secretariado Nacional para a Reabilitação e Integração das Pessoas com Deficiência, 1999.

MARTINS, M. Deficiência mental e desempenho profissional. 2001. Dissertação (Mestrado) - Secretariado Nacional para a Reabilitação e Integração das Pessoas com Deficiência, Lisboa, 2001.

MOSCOVICl, S. La psychanalyse, son image, son public. Paris: PUF, 1961.

PORTUGAL. Lei n 38/2004, de 18 de agosto de 2004. Define as bases gerais do regime jurídico da prevenção, habilitação e participação da pessoa com deficiência. Diário da República, Lisboa, n. 194, p. 5232, 18 ago. 2004. I Série-A.

PORTUGAL. Portaria 1102/97, de 3 de novembro de 1997. Diário da República, Lisboa, n. 254, 1997. I -B Série. Disponível em: <http://www.dre.pt/pdfgratis/1997/1 1/ 254B00.pdf >. Acesso em: 27 nov. 2007.

PORTUGAL. Secretaria de Estado da Educação e Inovação. Despacho n ${ }^{\circ} 22 / \mathrm{SEEl} / 96$, de 20 de abril de 2007. Diário da República, Lisboa, 19 jun. 1996.

PORTUGAL. Secretariado Nacional para a Reabilitação e Integração das Pessoas com Deficiência. A orientação para a formação profissional de jovens com deficiência intelectual. Lisboa, 1997.

. Transição para a vida activa dos jovens deficientes. Lisboa, 1995.

Recebido em: 28/02/2007

Aceito para publicação em: 17/10/2007 